\title{
2D transition metal-TCNQ sheets as bifunctional single-atom catalysts for oxygen reduction and evolution reaction (ORR/OER)
}

Deng, Qingming; Zhao, Jiong; Wu, Tiantian; Chen, Guibin; Hansen, Heine Anton; Vegge, Tejs

Published in:

Journal of Catalysis

Link to article, DOI:

10.1016/j.jcat.2018.12.012

Publication date:

2019

Document Version

Peer reviewed version

Link back to DTU Orbit

Citation (APA):

Deng, Q., Zhao, J., Wu, T., Chen, G., Hansen, H. A., \& Vegge, T. (2019). 2D transition metal-TCNQ sheets as bifunctional single-atom catalysts for oxygen reduction and evolution reaction (ORR/OER). Journal of Catalysis, 370, 378-384. https://doi.org/10.1016/j.jcat.2018.12.012

\section{General rights}

Copyright and moral rights for the publications made accessible in the public portal are retained by the authors and/or other copyright owners and it is a condition of accessing publications that users recognise and abide by the legal requirements associated with these rights.

- Users may download and print one copy of any publication from the public portal for the purpose of private study or research.

- You may not further distribute the material or use it for any profit-making activity or commercial gain

- You may freely distribute the URL identifying the publication in the public portal 


\title{
Two-dimensional Transition Metal-Tetracyanoquinodimethane (TM-TCNQ) Sheets as High-Activity Bifunctional Single-Atom Catalysts toward ORR and OER
}

\author{
Qingming Deng, ${ }^{a, b}$, Jiong Zhaoc, Tiantian Wu ${ }^{b}$, Guibin Chen ${ }^{a}$, Heine Anton Hansen*b, Tejs Vegge*b \\ ${ }^{a}$ Physics department and Jiangsu Key Laboratory for Chemistry of Low-Dimensional Materials, Huaiyin Normal University, Huaian 223300, China. \\ ${ }^{b}$ Department of Energy Conversion and Storage, Technical University of Denmark, Fysikvej, 2800 Kgs. Lyngby, Denmark. \\ ${ }^{c}$ Department of Applied Physics, The Hong Kong Polytechnic University, Kowloon, Hong Kong.
}

\section{ARTICLE INFO}

Article history:

Received

Received in revised form

Accepted

Available online
Keywords:

Computational screening

Oxygen Reduction Reaction

Oxygen Evolution Reaction

Bifunctional ORR/OER Catalyst

Density Functional Theory

\section{ABSTRACT}

Searching for stable, low-cost and active electrocatalysts for the oxygen reduction reaction (ORR) and oxygen evolution reaction (OER) to reduce use of precious platinum family is of great significance for large-scale commercialization of fuel cells and electrolyzers, but still remains a big challenge. Based on density functional theory (DFT), we systemically investigate two-dimensional transition metal based tetracyanoquinodimethane (referred to as TM-TCNQ, TM $=\mathrm{Cr}-\mathrm{Zn}, \mathrm{Ru}-\mathrm{Ag}, \mathrm{Pt}, \mathrm{Ir}$ ) monolayers, whose metal centers are distributed orderly and separately. After considering stabilities, conductivities and reaction mechanisms in acid solutions, the synthesized Fe-TCNQ monolayer is found to exhibit excellent catalytic activity for ORR with a very low overpotential of $0.35 \mathrm{~V}$ via four-electron reaction, which is lower than that of Pt metal of $0.48 \mathrm{~V}$. The catalytic performances of Ir-, Co-TCNQs for OER are identified as the highest two among the 12 candidates. By applying grafting axial ligands and external strain, the adsorption strength of reaction intermediates on TM reactive sites can further be tuned and resulting in enhanced activities of Fe-, Co- and Mn-TCNQs for the ORR/OER. Most importantly, FeTCNQ-Cl ( $\eta=0.32 / 0.34 \mathrm{~V})$, then following Mn-TCNQ-Cl ( $\eta=0.41 / 0.44 \mathrm{~V}$ ) and Mn-TCNQ-CO ( $\eta=0.33 / 0.54$ V) are predicted as high-activity bifunctional catalysts for the ORR/OER reactions with modified scaling relations of adsorbates, whose catalytic activities are even higher than the two best commercial electrocatalysts Pt (ORR: $\eta=0.48 \mathrm{~V}$ ) and RuO2 (OER: $\eta=0.41 \mathrm{~V}$ ). In addition, as novel synthesized singleatom catalysts, Fe-TCNQ and Mn-TCNQ possess excellent conductivity with fast electron transfer during the catalytic processes. These results might revive such $2 \mathrm{D}$ monolayer materials to design durable, low-cost, and efficient catalysts of ORR/OER in metal-air batteries and fuel cells.

2018 Elsevier Ltd. All rights reserved.

\section{Introduction}

The rising energy demand and depletion of fossil fuels have led to increasing interest in alternative energy sources. Additionally, fossil fuels are not renewable and generate deleterious combustion products such as $\mathrm{CO}, \mathrm{CO}_{2}, \mathrm{NO}, \mathrm{SO}_{2}$, and even hazards of heavy metal contamination posing serious challenges to human health, and environmental protection ${ }^{1}$. Sustainable power generation technologies are regarded as a promising solution, and a good example of such technologies is the proton exchange membrane (PEM) fuel cell, ${ }^{2,3}$ where hydrogen is oxidized at the anode producing protons which are transported through the membrane to the cathode where the oxygen reduction reaction (ORR) takes place during the production of water. However, slow oxygen kinetics of cathode and the use of precious metals based electrocatalysts, such as platinum $(\mathrm{Pt})$, hinder widespread commercialization $^{4}$. Likewise, the oxygen evolution reaction (OER) in water splitting electrocatalysts also requires noble metals namely ruthenium or iridium-based catalysts ${ }^{5-7}$. Thus, scientists are continuously seeking new families of low-cost electrocatalysts whose catalytic performances are comparable or even higher than those of noble metals based materials ${ }^{8}$. Moreover, finding bifunctional ORR and OER electrocatalyst is a key step in rechargeable metal-air batteries and regenerative fuel cell technologies ${ }^{9}$. Any technical breakthrough would therefore be greatly beneficial for easing the contradiction between supply and demand of energy and solving the environmental problems with 
burning fossil fuels. Metal-free electrodes have recently attracted attention as alternative to rare metal containing catalysts that can be used to catalyse the ORR or OER effectively ${ }^{10}$. For instance, vertical aligned nitrogen-doped carbon nanotube (VA-NCNT) arrays can catalyse a $4 \mathrm{e}^{-}$ORR process with a 3-times higher electrocatalytic activity and better long-term operational stability than that of widely used platinum/C electrodes ${ }^{11}$. Another way to reduce the usage of precious metals is mixing or alloying with cheaper metals, as the adsorption of reaction intermediates can be tuned to enhance the ORR or OER activity. The third approach involves the replacement of noble metals with much cheaper $3 d$ transition-metal catalysts supported on one or two dimensional materials. Typical examples are the transition metal- $\mathrm{N}_{4}$ macrocycles $\left(\mathrm{TM}-\mathrm{N}_{4}\right)$, e.g. phthalocyanine (TM-Pc) $)^{12-17}$, TMporphyrin-like complexes (TM-PP) $)^{18-20}$ and TM coordinate hexaaminobenzene-base polymer (TM-HAP) $)^{21,22}$, whose catalytic performances have been extensively studied both experimentally and theoretically. One big advantage of two dimensional single-atom catalysts (SACs) is that the various kinds of single metal atom sites are ordered and strongly anchored into the pores offering great potential for achieving high-activity catalysts with maximal usage of the transition metals. Besides, most of such two dimensional metal-organic frameworks are metallic allowing fast electron transport, which is particularly important for high activity electrocatalysts.

Analogous to the TM-N 4 complexes discussed above, twodimensional transition metal-tetracyanoquinodimethane (TMTCNQ) with four-coordinated metal structure have been synthesized with unique electronic, magnetic, and photoactive properties ${ }^{23-27}$. Wang et al. predicted Fe-TCNQ can serve as an efficient electrocatalyst for the ORR in acidic and alkaline conditions by $\mathrm{DFT}^{28}$. The activity range of the TM-TCNQs remains, however, largely unexplored, and their capacity as bifunctional ORR/OER electrocatalyst is still unknown. Inspired by the realized structures and the present simulations, we therefore systematically investigate twelve TM-TCNQs' stabilities, structures, and catalytic behaviors for the ORR and the OER by using first-principle calculations $(\mathrm{TM}=\mathrm{Cr}, \mathrm{Mn}, \mathrm{Fe}, \mathrm{Co}, \mathrm{Ni}, \mathrm{Cu}, \mathrm{Ru}$, $\mathrm{Rh}, \mathrm{Ir}, \mathrm{Pt}, \mathrm{Pd}, \mathrm{Ag})$. Our results reveal that Fe-TCNQ possesses the highest catalytic activity for the ORR with a rather low thermodynamic overpotential $(\eta)$ of $0.35 \mathrm{~V}$ via a four-electron reduction; this overpotential is noticeably lower than on the widely used Pt metal ${ }^{20,29,30}$. The catalytic performances of Ir-, Co-TCNQs for the OER are identified as the highest among 12 candidates. Grafting axial ligands and applying external strain can further enhance the activity, especially towards the OER, attributed to modify scaling relations of intermediates. Most importantly, Fe-
TCNQ and Mn-TCNQ with ligands of $\mathrm{Cl}$ and Mn-TCNQ with CO are predicted as bifunctional ORR/OER catalysts whose catalytic activities are comparable or even higher than the two best electrocatalysts $\mathrm{Pt}^{20,29,30}$ and $\mathrm{RuO}_{2}{ }^{31}$.

\section{Computational Methods}

All calculations in this study are carried out using spin-polarized density function theory (DFT) calculations as implemented in the Vienna $a b$ initio simulation package (VASP) ${ }^{7,22}$ to explore the activities for the ORR and the OER on TM-TCNQ monolayers. The exchange-correlation interactions are approximated by the RPBE functional ${ }^{32}$ within the generalized gradient approximation $(\mathrm{GGA})^{33}$, which provide better chemisorption energies than PBE. The kinetic energy cutoff of the plane-wave basis set is $500 \mathrm{eV}$, and dipole corrections are applied in the direction perpendicular to the TM-TCNQ plane. The thickness of the vacuum layer between TM-TCNQ planes is set to be more than $20 \AA$, which is sufficiently large to avoid interlayer interactions. The electronic SCF tolerance is set to $10^{-5} \mathrm{eV}$. Fully relaxed geometries and lattice constant are obtained by optimizing all atomic positions until the HellmannFeynman forces are below $0.02 \mathrm{eV} / \AA$. The k-point sampling is $4 \times 4 \times 1$ in the first Brillouin zone for structural optimizations, while a $8 \times 8 \times 1$ sampling is used for the density of states (DOS) calculations. VASP input files are prepared by the atomistic simulation environment (ASE) ${ }^{34}$. The structures of transition state (TS) are identified by the climbing image nudged elastic band method $(\mathrm{CI}-\mathrm{NEB})^{35}$. At least eight intermediate images are constructed along the reaction pathway between the initial state (IS) and the final state (FS) with a spring force of $5.0 \mathrm{eV} / \AA$. The minimum energy path is optimized with the fast inertial relaxation engine (FIRE) ${ }^{36}$ until the maximum force on the band is below $0.05 \mathrm{eV} / \AA$.

The DFT formation energies of $\mathrm{OOH}^{*}, \mathrm{O}^{*}$, and $\mathrm{OH}^{*}$ are calculated with reference to $\mathrm{H}_{2} \mathrm{O}(\mathrm{g})$ and $\mathrm{H}_{2}(\mathrm{~g})$ according to the following equations (1)-(3):

$$
\begin{aligned}
& \Delta E_{\mathrm{ads}}\left(\mathrm{OOH}^{*}\right)=E_{\mathrm{TCNQ}-\mathrm{OOH}}-E_{\mathrm{TCNQ}}-\left(2 E_{\mathrm{H} 2 \mathrm{O}}-3 / 2 E_{\mathrm{H} 2}\right) \\
& \Delta E_{\mathrm{ads}}\left(\mathrm{O}^{*}\right)=E_{\mathrm{TCNQ}-\mathrm{O}}-E_{\mathrm{TCNQ}}-\left(E_{\mathrm{H} 2 \mathrm{O}-} E_{\mathrm{H} 2}\right) \\
& \Delta E_{\mathrm{ads}}\left(\mathrm{OH}^{*}\right)=E_{\mathrm{TCNQ}-\mathrm{OH}}-E_{\mathrm{TCNQ}}-\left(E_{\left.\mathrm{H} 2 \mathrm{O}-1 / 2 E_{\mathrm{H} 2}\right)}\right.
\end{aligned}
$$

where $E_{\mathrm{TCNQ}} \mathrm{OOH}, E_{\mathrm{TCNQ}} \mathrm{O}, E_{\mathrm{TCNQ}}$-o are the energies of adsorbate binding to the transition metal of TCNQ complexes, $E_{\mathrm{H} 2 \mathrm{O}}$ and $E_{\mathrm{H} 2}$ are the total energy of single isolated $\mathrm{H}_{2} \mathrm{O}$ and $\mathrm{H}_{2}$ molecule, respectively.

The computational hydrogen electrode (CHE) model ${ }^{29}$ is applied to evaluate the change in Gibbs free energy of adsorbates by equation (4). 
$\Delta G=\Delta E_{\mathrm{ads}}+\Delta E_{\mathrm{ZPE}}+T \Delta S+\Delta G_{\mathrm{U}}$

where $E_{\text {ads }}$ is calculated from equation (1) to (3). $\Delta E_{Z P E}$ and $T \Delta S$ are the zero point energy change and entropy change upon adsorption, respectively. Here, $\Delta E_{Z P E}+T \Delta S$ is approximated to be $0.4,0.05$ and $0.35 \mathrm{eV}$ for $\mathrm{OOH}, \mathrm{O}$, and $\mathrm{OH}$ adsorbates, respectively ${ }^{29,37,38} . \Delta G_{\mathrm{U}}=-n e U$, where $n$ is the number of electrons transferred and $U$ is the electrode potential versus the reversible hydrogen electrode ${ }^{19}$. Solvation energies are added to $\Delta G$ by -0.3 $\mathrm{eV}$ for $\mathrm{OH}$ and $\mathrm{OOH}$ adsorbates followed by previous studies ${ }^{37}$.

\section{Results and Discussion}

Irreversible detachment of the central transition metal from the catalyst significantly limits catalyst durability. To elucidate the stabilities of TM-TCNQ monolayers, we firstly examine the energetic difference $\left(E_{\text {diff }}\right)$ between the embedding energy of the metals $\left(E_{\mathrm{emb}}\right)$ and the cohesive energy $\left(E_{\mathrm{c}}\right)$ of the bulk metal according to the equation:

$E_{\text {diff }}=E_{\mathrm{emb}}-E_{\mathrm{c}}=\left(E_{\mathrm{TM}}-\mathrm{TCNQ}-E_{\mathrm{TCNQ}}-E_{\mathrm{M}}\right)-\left(E_{\mathrm{bulk}}-\mathrm{N} E_{\mathrm{M}}\right) / \mathrm{N}$

where $E_{\mathrm{TM}-\mathrm{TCNQ}}, E_{\mathrm{TCNQ}}, E_{\text {bulk, }} E_{\mathrm{M}}$ are total energies of the TMTCNQ system, the metal-free TCNQ, the bulk metal unit cell containing $\mathrm{N}$ metal atoms and the isolated single metal in the same slab, respectively. Negative values of $E_{\text {diff, here in the range from }}$ -0.81 to $-2.89 \mathrm{eV}$ (Table.S1), indicate the metal atoms prefer to be embedded into the TCNQ rather than forming bulk metal or clusters likely because of the very strong coordination bonds formed as nitrogen atoms donate $2 p$ electron pairs to the vacant $d$ orbitals of metal. Thus, $\mathrm{Cr}$ and Mn-TCNQ are expected to have the largest $E_{\text {diff }}$ due to the relative high fraction of vacant $d$ orbitals. Secondly, the removal energy $\left(\mathrm{E}_{r e}\right)$ is calculated to evaluate the feasibility of metal substitution by hydrogenation of TCNQ in solution by the following equation:

$E_{\mathrm{re}}=E_{\mathrm{TM}-\mathrm{TCNQ}}+E_{\mathrm{H} 2}-E_{\mathrm{H} 2-\mathrm{TCNQ}}-E_{\mathrm{bulk}} / \mathrm{N}$

where $E_{\mathrm{TM}-\mathrm{TCNQ}}, E_{\mathrm{H} 2}, E_{\mathrm{H} 2-\mathrm{TCNQ}}, E_{\text {bulk }}$ are total energies of the TMTCNQ system, hydrogenated TCNQ, $\mathrm{H}_{2}$ molecule and basic unit cell containing $\mathrm{N}$ metal atoms, respectively. Large negative values of $E_{r e}$ for Cr-, Mn-, Fe-TCNQ (>-0.28eV) reveal that these metal atoms can coordinate strongly with four nitrogen atoms in a square pyramidal configuration rather than being substituted by $\mathrm{H}_{2}$ (or protons and electrons) in Table.S1. However, the central metal atoms are more easily substituted by protons in $\mathrm{Ru}-, \mathrm{Pd}-, \mathrm{Ag}-$, and Pt-TCNQs because of their larger positive values of $E_{\mathrm{re}}(>0.28 \mathrm{eV})$. Hydrogen substitution of the central metal atom in $\mathrm{Co}-, \mathrm{Rh}_{-}, \mathrm{Ni}-$, $\mathrm{Cu}-$, and Ir-TCNQ are moderate due to small removal energies from -0.11 to $0.16 \mathrm{eV}$. Thirdly, in acidic electrochemical electrolyte transition metals might oxidize and the most stable form of the transition metal can be a cation rather than the bulk

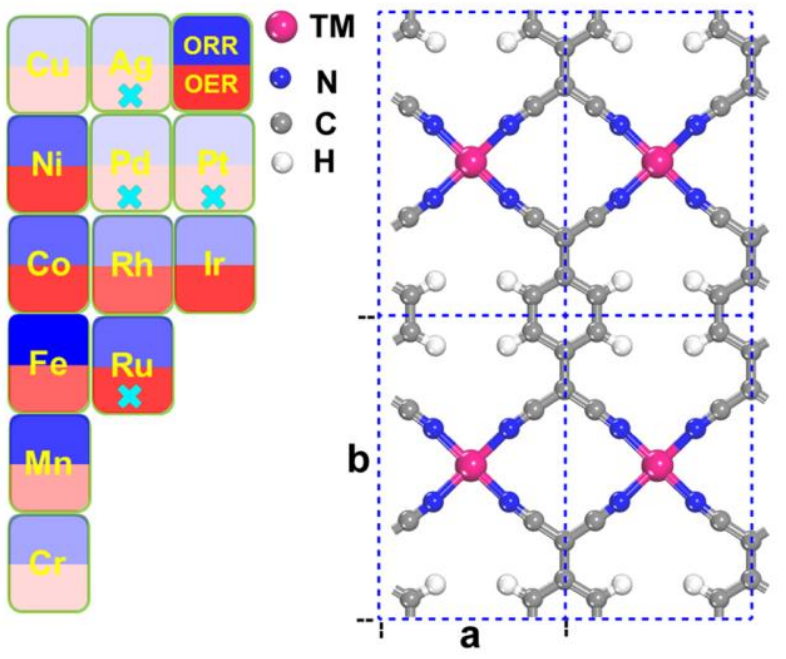

Figure 1. Illustration of 12 TM-TCNQ candidates. Bluer and redder colours labelled correspond to higher activities of ORR and OER. The colours of transition metals (TM), nitrogen(N), carbon $(\mathrm{C})$, hydrogen atoms $(\mathrm{H})$ are in magenta, blue, gray and white respectively. TM-TCNQs with crosses are ruled out because they do not meet the stabilities' criterion.

metal. To access the stability in acid of these corroding transition metals, we also calculate the acidic stability as

$E_{\text {acid }}=E_{\text {diff }}+n e\left(U-U_{0}\right)$

for the corroding elements. Here $n$ is the number of electrons transferred in the oxidation, $e$ is the elementary charge, $U$ is the catalyst potential, and $U_{0}$ is the experimental reversible potential for the metal redox reaction ${ }^{18}$. We see (in Table.S1, Supporting Information) that early $3 d$ transition metals in TM-TCNQ are thermodynamically unstable at a representable operating potential of $0.75 \mathrm{~V}$ vs RHE, and that $\mathrm{Fe}$ and $\mathrm{Co}$ are less unstable than $\mathrm{Cr}$ and $\mathrm{Mn}$. In brief, by applying three descriptors to evaluate the stability of the TM-TCNQ monolayers, the stability of these candidates towards metal atoms clustering follow the trend $\mathrm{Cr}>$ $\mathrm{Mn}>\mathrm{Fe}>\mathrm{Co}>\mathrm{Rh}>\mathrm{Cu}>\mathrm{Ni}>\mathrm{Ir}$ for TCNQ monolayers in aqueous solution. At oxidizing operating potentials, the trend is largely reversed $\mathrm{Ir}>\mathrm{Rh}>\mathrm{Cu}>\mathrm{Co}>\mathrm{Fe}>\mathrm{Ni}>\mathrm{Mn}>\mathrm{Cr}$. While, the unlisted candidates should be ruled out due to unsatisfying the stability criterion.

The optimized structure of Fe-TCNQ is shown in Fig. 1, as an example. The TM-TCNQs have rectangular unit cells with lattice constants listed in Table S1. Similar to graphene and boron nitride sheets, the structures of all the candidates are all perfect $2 \mathrm{D}$ atomic sheets without buckling. The bond length between $\mathrm{Fe}$ and the nearest neighboring $\mathrm{N}$ atom is $1.853 \AA$ which is $5 \%$ shorter than the value of $1.946 \AA$ in FePc. Except $\mathrm{Cu}, \mathrm{Pd}$, and Ag, the TM-N bond lengths of TCNQ are all shorter than the TM-Pc bond length as shown in Table S1. Bader charge analysis suggests each highly electronegative nitrogen atom carries $-1.24|\mathrm{e}|$, and the neighbouring $\mathrm{Fe}$ and $\mathrm{C}$ atoms carry $1.19 \mathrm{e} \mid$ and $0.77 \mathrm{e} \mid$ positive 
charge, indicating that the bonding between $\mathrm{N}$ and $\mathrm{Fe} / \mathrm{C}$ is largely covalent. In most cases, the spin and oxidation states of TMTCNQ complexes listed in Table S1 are quite similar to other metal- $\mathrm{N}_{4}$ coordinate materials, such as TM-Pc ${ }^{17}, \mathrm{TM}-\mathrm{N}_{4}-\mathrm{gra}^{37}$,

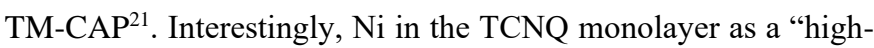
spin" complex carries $1.14 \mu_{\mathrm{B}}$ magnetic moment leading to a +2 oxidation state, whereas Ni-CAP is nonmagnetic (based on a previous study ${ }^{21}$ and our calculations). Thus, small differences in atomic geometries of TM-N 4 moieties can have quite different electronic structure leading to great influence on adsorbates' binding energies and therefore their catalytic activities for the ORR the and OER.

As proposed by Nørskov et al. ${ }^{29}$, the activity of the ORR and the OER is mainly governed by the adsorption energy of key reaction intermediates, because the kinetics of proton coupled electron transfer to the reaction intermediates is fast even at room temperature. According to the Sabatier principle, if intermediates interact too strongly with TM-TCNQ monolayer, the active sites of the catalyst are poisoned; whereas, if the interactions are too weak, it is difficult to activate reactants or intermediates and launch the catalytic process. Therefore, identifying promising materials with "just right" adsorption energies of the reaction intermediates is a challenge. Via the four-electron reaction pathway, the overall formation energy toward ORR is $4.92 \mathrm{eV}$, so the ideal adsorption free energies of $\mathrm{OOH}^{*}, \mathrm{O}^{*}$ and $\mathrm{OH}^{*}$ are 3.69, 2.46, and $1.23 \mathrm{eV}$ with consecutive intermediates differing by $1.23 \mathrm{eV}$. In Table S2, the adsorption free energies of 12 candidates are reported. The trend in intermediate binding strength is $\mathrm{Cr}>\mathrm{Ru}>$ $\mathrm{Mn}>\mathrm{Fe}>\mathrm{Co}>\mathrm{Ni}>\mathrm{Ir}>\mathrm{Rh}>\mathrm{Cu}>\mathrm{Pd}>\mathrm{Pt}>\mathrm{Ag}$. It is well known the adsorption energies correlate strongly with $d$-band centres ${ }^{32,39}$. Deep/negative $d$-band centers correspond to low reactivities of the transition metal when only a small proportion of $d$ orbitals lie above the Fermi level. From figure S1 and table S2, we can see that the trend in $d$-band centers follows the trend in adsorption energies with the increase of the atomic number of the TM atoms. Thus, the performance of the ORR and the OER can be well described by the trend in $d$-band centres, which may guide better design of electrocatalysts. Besides, the electronic local density of states (LDOS) projected on the TM and the total density of states (DOS) reveal the TM-TCNQs are all found to be metallic at the applied level of theory (GGA-DFT), except Pt-TCNQ whose band gap reaches $0.71 \mathrm{eV}$. Metallic conductivity guarantees fast electron transfer during the electrochemical reactions, a feature consistent with TM-CAPs ${ }^{21}$.

First, we consider a dissociative mechanism where chemisorbed $\mathrm{O}_{2}$ dissociates into two $\mathrm{O}$ atoms on the catalyst surface. From the structures of TM-TCNQs, because the central metal atom is isolated and embedded into the plane of the TM-TCNQ, we expect the catalyst is unable to provide enough reactive sites to accommodate two $\mathrm{O}$ atoms and the barrier should be quite high. A previous study ${ }^{28}$ found that $\mathrm{O}_{2}$ dissociation is difficult, as it has a large barrier of over $2 \mathrm{eV}$ on Fe-TCNQ. Because stronger binding of adsorbates usually corresponds to a lower barrier of $\mathrm{O}_{2}$ dissociation ${ }^{40}$, we only need to consider $\mathrm{O}_{2}$ dissociation on $\mathrm{Cr}$ - and Mn-TCNQs in the present study. With high activation energies of $1.14 \mathrm{eV}$ and $1.34 \mathrm{eV}$ for $\mathrm{O}_{2}$ dissociation calculated by CI-NEB method, the dissociative mechanism is unlikely to occur, and we turn our attention to the associative mechanism in the following.

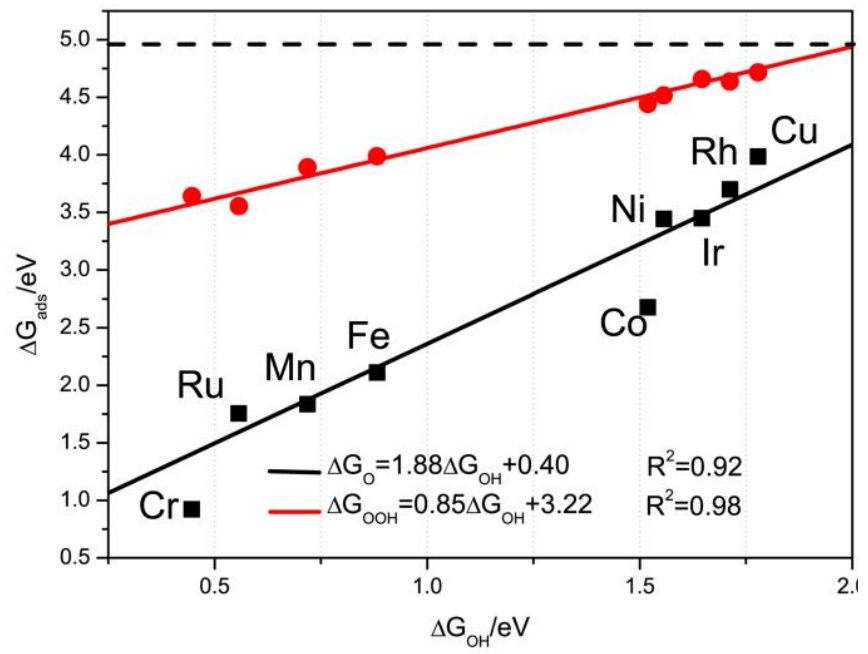

Figure 2. Scaling relations between the adsorption energies of adsorbates on TM-TCNQ monolayers. Black: ${ }^{*} \mathrm{O}$ vs. ${ }^{*} \mathrm{OH}$; red: $* \mathrm{OOH}$ vs. ${ }^{*} \mathrm{OH}$. The dashed line shows the $\mathrm{O}_{2}$ initial state at $4.92 \mathrm{eV}$.

\section{The oxygen reduction reaction and oxygen evolution reaction catalyzed by TM-TCNQ.}

We investigate 4-electron ORR in acidic solution via the following pathway:

$$
\begin{aligned}
& *+\mathrm{O}_{2}(\mathrm{~g})+\mathrm{H}^{+}+\mathrm{e}^{-} \rightarrow \mathrm{OOH}^{*} \\
& \mathrm{OOH}^{*}+\mathrm{H}^{+}+\mathrm{e}^{-} \rightarrow \mathrm{O}^{*}+\mathrm{H}_{2} \mathrm{O} \\
& \mathrm{O}^{*}+\mathrm{H}^{+}+\mathrm{e}^{-} \rightarrow \mathrm{OH}^{*} \\
& \mathrm{OH}^{*}+\mathrm{H}^{+}+\mathrm{e}^{-} \rightarrow *+\mathrm{H}_{2} \mathrm{O}
\end{aligned}
$$

where * denotes an active site on the catalyst. According to equation (9)-(12), the reaction Gibbs free energy can be written as $\Delta G_{1}=\Delta G_{\text {ads }}\left(\mathrm{OOH}^{*}\right)-4.92 \mathrm{eV}$

$\Delta G_{2}=\Delta G_{\text {ads }}\left(\mathrm{O}^{*}\right)-\Delta G_{\text {ads }}\left(\mathrm{OOH}^{*}\right)$

$\Delta G_{3}=\Delta G_{\text {ads }}\left(\mathrm{OH}^{*}\right)-\Delta G_{\text {ads }}\left(\mathrm{O}^{*}\right)$

$\Delta G_{4}=-\Delta G_{\text {ads }}\left(\mathrm{OH}^{*}\right)$ 


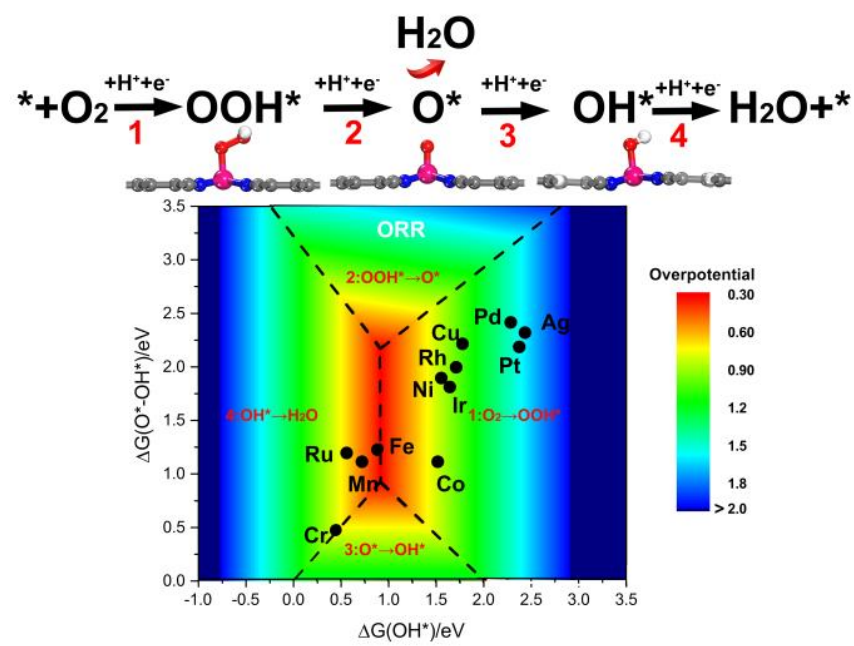

Figure 3. Four-electron-transfer ORR pathway through the intermediates $\mathrm{OOH}^{*}, \mathrm{O}^{*}$ and $\mathrm{OH}^{*}$, and contour map of the ORR overpotential $(\eta)$ as a function of Gibbs free energies of $\mathrm{O}^{*}-\mathrm{OH}^{*}$ and $\mathrm{OH}^{*}$. Oxygen $(\mathrm{O})$ atoms are coloured in red.

Figure 2 shows the scaling relations of $\Delta G\left(\mathrm{OH}^{*}\right)$ vs $\Delta G\left(\mathrm{O}^{*}\right)$ and $\Delta G\left(\mathrm{OH}^{*}\right)$ vs $\Delta G\left(\mathrm{OOH}^{*}\right)$. They can be expressed as a function of $\Delta G\left(\mathrm{OH}^{*}\right)$ by

$\Delta G\left(\mathrm{O}^{*}\right)=1.88 \Delta G\left(\mathrm{OH}^{*}\right)+0.40 \mathrm{eV}$

$\Delta G\left(\mathrm{OOH}^{*}\right)=0.85 \Delta G\left(\mathrm{OH}^{*}\right)+3.22 \mathrm{eV}$

Strong linear relationships of equations (17) and (18) with high coefficients of determination $\left(\mathrm{R}^{2}=0.92,0.98\right)$ and very small root mean square error $(0.09 \mathrm{eV}, 0.005 \mathrm{eV})$ can be found for $\mathrm{OH} v s \mathrm{O}$, and $\mathrm{OH} v s \mathrm{OOH}$, respectively. The slope of 0.85 and a constant separation of $3.22 \mathrm{eV}$ of $\mathrm{OH} v s \mathrm{OOH}$ have been attributed to the similar bond order of $\mathrm{M}-\mathrm{OH}$ and $\mathrm{M}-\mathrm{OOH}$ bonds, and is consistent with those of metal and metal oxide surfaces ${ }^{30,31} . \Delta G_{\text {ads }}$ is calculated from equations (1)-(4). The Gibbs free energy of $\mathrm{O}_{2}$ $(4.92 \mathrm{eV})$ is taken from the experimental value of the reaction $2 \mathrm{H}_{2} \mathrm{O} \rightarrow \mathrm{O}_{2}+2 \mathrm{H}_{2}$. The first step in the ORR pathway is $\mathrm{O}_{2}$ being hydrogenated to $\mathrm{OOH}^{*}$ through coupled proton electron transfer. Then $\mathrm{OOH}^{*}$ is attacked by an additional proton-electron pair to form atomic oxygen and a water molecule. $\mathrm{O}^{*}$ is then further hydrogenated to $\mathrm{OH}^{*}$, before the second $\mathrm{H}_{2} \mathrm{O}$ formed. We neglect the small barriers of proton coupled electron transfer ${ }^{41}$ in this work, in which case the reaction kinetics is only determined by the reaction free energy of each step. The activity of an ORR catalyst can be evaluated by the thermodynamic overpotential $(\eta)$. Based on the computational hydrogen electrode (CHE) model $^{29}$, the limiting potential $\left(\mathrm{U}_{\mathrm{lim}}\right)$ and the overpotential can be calculated from equations (19) and (20) by determining the greatest free energy increase of all reaction steps at the equilibrium potential $1.23 \mathrm{~V}$ of the $4 \mathrm{e}^{-} \mathrm{ORR}$ :

$\mathrm{U}_{\mathrm{lim}}=-\max \left\{\Delta G_{1}, \Delta G_{2}, \Delta G_{3}, \Delta G_{4}\right\} / \mathrm{e}$

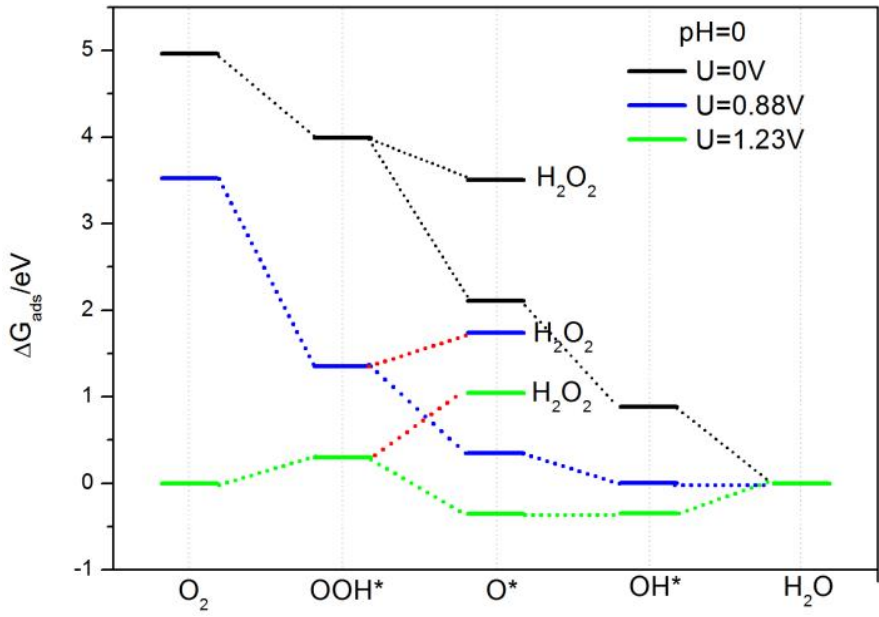

Figure 4. Gibbs free energy landscape of Fe-TCNQ for the ORR at different electrode potentials in an acidic medium.

$\eta=1.23-\mathrm{U}_{\mathrm{lim}}=1.23+\max \left\{\Delta G_{1}, \Delta G_{2}, \Delta G_{3}, \Delta G_{4}\right\} / \mathrm{e}$

Lower overpotential represents a better ORR performance. The overpotential is evaluated on the TM-TCNQs as a function of the two variables $\Delta G\left(\mathrm{O}^{*}-\mathrm{OH}^{*}\right)$ and $\Delta G\left(\mathrm{OH}^{*}\right)$ and is shown Fig. 3 . Here, $\Delta G_{\text {ads }}\left(\mathrm{OOH}^{*}\right)$ is approximated as a function of $\Delta G_{\text {ads }}\left(\mathrm{OH}^{*}\right)$ from the scaling relation between $\mathrm{OOH}^{*}$ and $\mathrm{OH}^{*}$ in Fig. 2. From the volcano plot in Fig. 3, the minimum possible $\eta$ is found as low as $0.3 \mathrm{~V}$. The best TM-TCNQ for the ORR is found to be FeTCNQ with $\eta=0.35 \mathrm{~V}$. This thermodynamic overpotential is even lower than that on $\operatorname{Pt}(111)(\eta=0.48 \mathrm{~V})$ calculated with the RPBE functional $^{20}$. The rate-determining step of the ORR on the FeTCNQ monolayer is the forth step of $\mathrm{OH}^{*}$ reduction to $\mathrm{H}_{2} \mathrm{O}^{*}$ which agrees with other macrocyclic Fe-N materials $^{15}$ 21, $42 . \mathrm{Mn}$ also exhibits very good activity $(\eta=0.51 \mathrm{~V})$ for ORR with the same rate-determining step as $\mathrm{Fe}$. $\mathrm{Cr}$ and $\mathrm{Ru}$-TCNQs have higher $\eta(0.78$ $\mathrm{V}, 0.67 \mathrm{~V}$ ), which are caused by their stronger adsorption of $\mathrm{OH}^{*}$. In contrast to this, transition metals from Co to Ag provide weak binding of the ORR intermediates resulting in low activities toward the ORR with the rate-determining step being $\mathrm{O}_{2}$ reduction to $\mathrm{OOH}^{*}$. Note that $\mathrm{Fe}$ almost reaches the top of the volcano, and weakening the interaction between $\mathrm{OH}^{*}$ and the metal in $e . g$. MnTCNQs or Ru-TCNQ will enhance the ORR activity, whereas increasing the interaction between $\mathrm{OH}^{*}$ (and $\mathrm{OOH}^{*}$ ) and $\mathrm{Co}-$ TCNQ or Ni-TCNQ will enhance activity as well.

Here, the two-electron (2e $)$ reduction of $\mathrm{O}_{2}$ to $\mathrm{H}_{2} \mathrm{O}_{2}$ is also taken into account though formation of $\mathrm{OOH}^{*}$ (eq. (21)) followed by

$\mathrm{OOH}^{*}+\mathrm{H}^{+}+\mathrm{e}^{-} \rightarrow *+\mathrm{H}_{2} \mathrm{O}_{2}$

where the unhydrogenated $\mathrm{O}$ atom in $\mathrm{OOH}^{*}$ is hydrogenated to form $\mathrm{H}_{2} \mathrm{O}_{2}$. Fig. 4 displays the free energy diagram the ORR via the two-electron and four-electron reductions on Fe-TCNQ at different electrode potentials, respectively. At $U=0$, all steps are exothermic, so the reaction can spontaneously occur on a FeTCNQ monolayer from $\mathrm{O}_{2}$ to $\mathrm{H}_{2} \mathrm{O}$. However, the formation of 


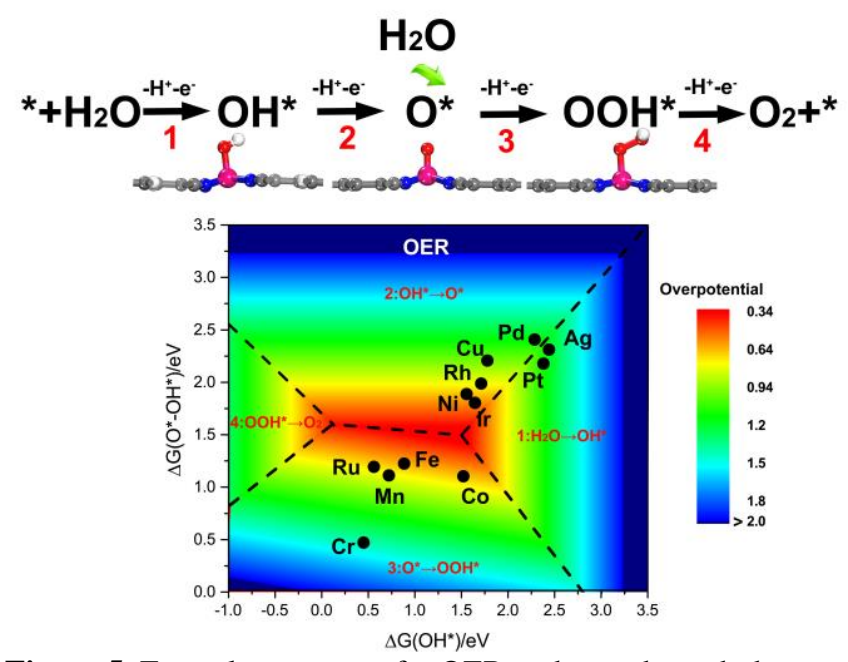

Figure 5. Four-electron-transfer OER pathway through the intermediates $\mathrm{OH}^{*}, \mathrm{O}^{*}$ and $\mathrm{OOH}^{*}$, and contour map of the OER overpotential $(\eta)$ as a function of Gibbs free energies of $\mathrm{O}^{*}-\mathrm{OH}^{*}$ and $\mathrm{OH}^{*}$.

$\mathrm{H}_{2} \mathrm{O}_{2}$ via the two-electron pathway is less exergonic than formation of $\mathrm{O}^{*}$ in the $4 \mathrm{e}^{-}$reduction, because the released free energy $(0.49 \mathrm{eV})$ by $\mathrm{H}_{2} \mathrm{O}_{2}$ is much less than the free energy (1.88 $\mathrm{eV}$ ) released in the process of converting $\mathrm{OOH}$ to $\mathrm{O}$. Therefore, when $\mathrm{U}>0.49 \mathrm{~V}$, the $\mathrm{H}_{2} \mathrm{O}_{2}$ formation from $\mathrm{OOH}$ is endothermic, while $\mathrm{O}^{*}$ formation from $\mathrm{OOH}^{*}$ is still downhill. When $\mathrm{U}=\mathrm{U}_{\lim }=0.88 \mathrm{~V}$, the free energy of $\mathrm{OH}^{*}$ to $\mathrm{H}_{2} \mathrm{O}$ become isoenergetic, and $\mathrm{H}_{2} \mathrm{O}_{2}$ formation is supressed. At the equilibrium potential for the $4 \mathrm{e}^{-}$reduction, the thermodynamic barrier is highest for the rate-determining step, which is the reduction of $\mathrm{OH}^{*}$ to $\mathrm{H}_{2} \mathrm{O}$.

The OER is the reverse reaction of the ORR. Thus, the overpotential can be rewritten as the following equation (22):

$\eta=\mathrm{U}_{\text {lim }}-1.23 \mathrm{~V}=\max \left\{-\Delta G_{1},-\Delta G_{2},-\Delta G_{3},-\Delta G_{4}\right\} / \mathrm{e}-1.23 \mathrm{~V}$

Fig. 5 indicates the ideal minimum $\eta$ is $0.34 \mathrm{~V}$ by using the scaling relation between $\mathrm{OOH}^{*}$ vs $\mathrm{OH}^{*}$ from Fig 2. The TM-TCNQs are distributed in three different zones corresponding to different ratedetermining steps, and most are quite far from the apex of the activity volcano. The two best catalysts for OER among the 12 candidates are identified as Co- and Ir-TCNQ with $\eta$ of 0.58 and $0.57 \mathrm{~V}$ respectively, which is about $0.15 \mathrm{~V}$ higher than $\mathrm{RuO}_{2}$ $(\eta=0.42 \mathrm{eV})^{31}$. Ni and $\mathrm{Fe}$ also exhibit reasonable activity with $\eta$ of ca. $0.65 \mathrm{~V}$, which agrees quantitatively with recently identified OER overpotential of $\mathrm{TM}^{-\mathrm{N}_{4}}$ materials $^{21,37}$ (TM=Fe, Co, Ni). According to the above discussion, there is still plenty of room to enhance the catalytic activity as none of the TM-TCNQs approaches the optimal $\eta$ for OER. From above stability selection, $\mathrm{Ru}$ atoms are found easily substituted by protons in aqueous solution. Considering this and cost, we will not study Ru-TCNQ monolayer in the following part.

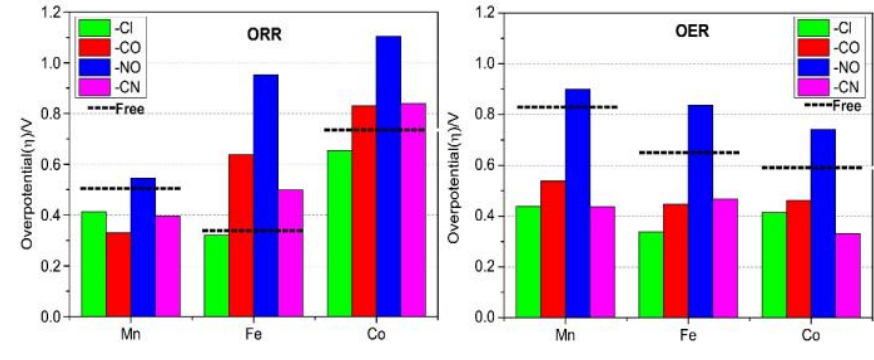

Figure 6. Overpotentials of TM-TCNQ (TM=Mn, Fe, Co) towards the ORR and the OER by coordinating $\mathrm{Cl}, \mathrm{CO}, \mathrm{NO}, \mathrm{CN}$ as axial ligands as well as ligand free monolayers for comparison, respectively.

Improving the catalytic performance by coordinating axial ligands

Coordinating an axial ligand to the metal centre is expected to be an effective approach ${ }^{42,43}$ to improve the performances of ORR and OER, which attribute to change of the properties of the metal centres and their interaction with the coordination configuration. For instance, improved ORR activity for $\mathrm{FeN}_{4} \mathrm{C}_{\mathrm{x}}$ in phosphoric acid electrolyte, was recently attributed to coordination to phosphate anions ${ }^{44}$. Moreover, ligand-field effects altering the chemical environment of the central TM sites may also lead to modified scaling relations between the reaction intermediates. In experiments, the five and six fold coordination of TM-4N complexes are common approaches to modificate their properties ${ }^{39}$. Therefore, inspired by this technology and a synthesised six fold coordination in Fe-TCNQ materials ${ }^{24}$, we study $\mathrm{Mn}$-, $\mathrm{Fe}-$ and CoTCNQ sheets near the vertex of volcano with four different ligands viz. cyano $(\mathrm{CN})$, carbon monoxide $(\mathrm{CO})$, nitrogen oxide $(\mathrm{NO})$, chlorine $(\mathrm{Cl})$.

The ligands are initially placed on one side of the monolayer, and the intermediates adsorbed on the other side. The ORR and OER overpotentials of Mn, Fe and Co-TCNQs with these ligands are shown in Fig. 6. Among these candidates, Fe-TCNQ-Cl exhibit very good catalytic performance $(\eta=0.32 / 0.34 \mathrm{~V})$ for bifunctional ORR/OER activity, then following Mn-TCNQ-Cl with $\eta$ less than $0.5 \mathrm{~V}$, whereas Mn-TCNQ-CO is also found to be an efficient bifunctional catalysis. The superb catalytic performance is ascribed to suitably weakened adsorption energies and violating the original scaling relations of adsorbates after grafting the appropriate ligands onto the metal centre (Fig. S2, Supporting Information). The NO ligand, however, decreases the activity toward the ORR and the OER in Fig.6. The reason is that $\Delta G\left(\mathrm{OH}^{*}\right)$ increases too much $(>0.3 \mathrm{eV})$ compared to ligand-free case.

From the discussion above, the OER overpotential can become lower with increasing $\Delta G\left(\mathrm{OH}^{*}\right)$ for Mn- and Fe-TCNQ. The CN ligand plays such role by weakening $\Delta G\left(\mathrm{OH}^{*}\right)$ by $0.15-0.35 \mathrm{eV}$ 


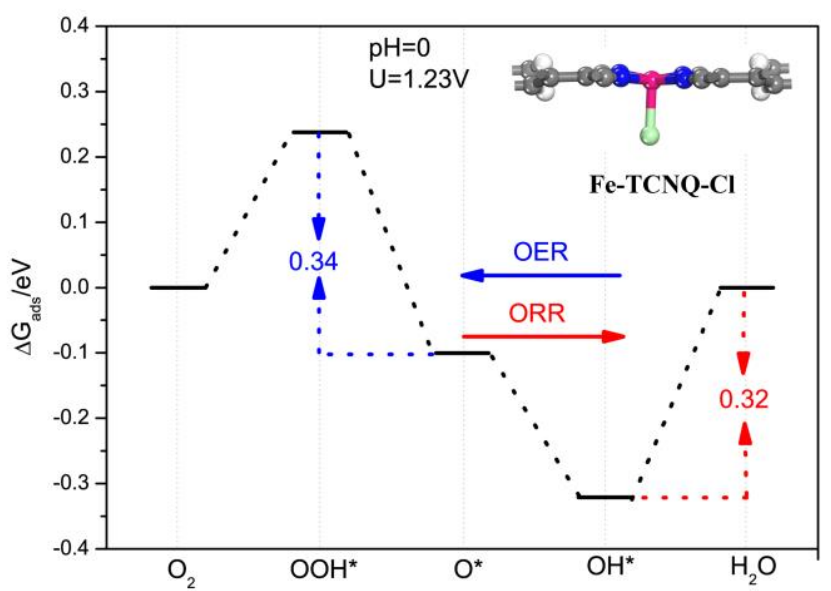

Figure 7. Gibbs free energy diagram of bifunctional Fe-TCNQ with an axial $\mathrm{Cl}$ grafting ligand for the ORR and the OER at the $4 \mathrm{e}^{-}$equilibrium potential. The overpotentials $(\eta)$ in Volts are marked in red and blue.

and resulting in lower $\eta$ for the OER. However, taking into account the competition between ligands and intermediates, we find a second CN ligand binds strongly to TCNQ with adsorbate formation energies in the in range from -0.71 to $-1.14 \mathrm{eV}$ in Fig. $\mathrm{S} 3$, so $\mathrm{CN}$ may block the active sites by forming 6-fold coordinated metal sites. Meanwhile, the binding strengths of the second ligands are relative weaker for $\mathrm{CO}(-0.54-0.02 \mathrm{eV})$ and $\mathrm{Cl}(-0.74-0.4 \mathrm{eV})$. Thus, $\mathrm{Cl}$ and $\mathrm{CO}$ molecules are more promising ligands than $\mathrm{CN}$ to improve activity.

Rationalizing the change in intermediate binding energies based on, e.g., Bader charge analysis does not reveal any clear correlation between binding energies and charges of the central metal atoms in the TM-TCNQ monolayers. Central metal atoms carry more positive charge after grating ligands except in the case of Mn-TCNQ-CO, while the $E_{\text {ads }}$ values of all the adsorbates decrease consistently. Thus, coordinating various ligands can greatly change the adsorption profiles and violate the original scaling relation providing more space to rational design high active catalysis. We note that recent experiment also indicates $\mathrm{Cl}$ anion are not able to fully poison iron atoms of $\mathrm{FeN}_{4} \mathrm{C}_{\mathrm{x}}$ moieties ${ }^{44}$, but can influent the activity of ORR in the electrolyte solution suggesting moderate binding energy of $\mathrm{Fe}-\mathrm{Cl}$ which is consistent with our DFT calculation. Besides, Fe-TCNQ ${ }^{24}$ and $\mathrm{Mn}-\mathrm{TCNQ}^{45,}{ }^{46}$ have been produced at present. Herein, we propose $\mathrm{Fe}-\mathrm{TCNQ}-\mathrm{Cl}(\eta=0.32 / 0.34 \mathrm{~V})$, then following $\mathrm{Mn}$ TCNQ-Cl $(\eta=0.41 / 0.44 \mathrm{~V})$ and Mn-TCNQ-CO $(\eta=0.33 / 0.54 \mathrm{~V})$ as bifunctional catalysts for the ORR/OER reactions with quite high catalytic activities comparable to the two best ORR and OER electrocatalysts $\mathrm{Pt} \quad(\eta=0.48 \mathrm{eV})^{20}$ and $\mathrm{RuO}_{2} \quad(\eta=0.42 \mathrm{eV})^{31}$, respectively. Strain engineering in $2 \mathrm{D}$ materials is a feasible technology to achieve tunable electronic properties ${ }^{47-50}$. Previous studies reveal that external strain can change the binding of adsorbates $^{51}$ due to shifts in $d$-band centers ${ }^{15}$. Inspired by this approach, we also perform extensive calculations of TM-TCNQ
( $\mathrm{TM}=\mathrm{Mn}, \mathrm{Fe}, \mathrm{Co}, \mathrm{Ir}$ ) to examine effect of strain on the catalytic performance by applying between $-3 \%$ compressive to $3 \%$ tensile strain. The result indicates that $\eta$ of Co-TCNQ for OER is decreased from $0.58 \mathrm{~V}$ to $0.35 \mathrm{~V}$ under $3 \%$ compressive strain. However, the catalytic performances of other candidates (TM=Mn, $\mathrm{Fe}, \mathrm{Ir}$ ) for ORR/OER under strain are not improved accordingly (see details in Supporting Information).

\section{Conclusion}

To summarize, we have systematically investigated stabilities and catalytic behaviors of twelve TM-TCNQs toward the ORR and the OER by using density functional theory. The adsorption strength of reaction intermediates on TM reactive sites is strongly correlated to the $d$-band centers. Except for Pt-TCNQ, the studied catalysts possess excellent conductivity for fast electron transfer during the catalytic processes. Fe-TCNQ is found to exhibit the highest catalytic activity for ORR with $\eta$ of $0.35 \mathrm{~V}$ via a fourelectron reaction, which is noticeably higher than the widely used Pt metal. The catalytic performances of Ir-, Co-TCNQs for the OER are identified as the highest among 12 candidates. Grafting axial ligands or applying external strain to the TM-TCNQs can further tune the adsorptive profiles of adsorbates leading to enhancement of ORR and OER activities, especially for the OER. Importantly, Fe-TCNQ and Mn-TCNQ monolayers with $\mathrm{Cl}$ ligands and Mn-TCNQ with a CO ligand are predicted as efficient bifunctional ORR/OER catalysts whose catalytic activities are comparable or even higher than the two best electrocatalysts Pt and $\mathrm{RuO}_{2}$. As Fe-TCNQ and Mn-TCNQ being synthesized at present, our findings open novel ways to design durable, non-precious metal, efficient catalysts of ORR/OER in metal-air batteries and fuel cells.

\section{Acknowledgements}

This work was supported by the People Programme (Marie Curie Actions) of the European Union's Seventh Framework Programme (FP7/2007-2013) under REA grant agreement no. 609405 (COFUNDPostdocDTU), the National Science Foundation of China (21703076), the Natural Science Foundation of Jiangsu Province of China (BK20170466), Six Talent Peaks Program of Jiangsu Province (XCL-014), Natural Science Research Program of Jiangsu Higher Education Institutions of China (18KJA140001) and HK PolyU Project (1-ZE8C).

\section{Supplementary Material}

Electronic Supplementary Information (ESI) available: Properties of TM-TCNQ monolayers. Free energy of $\mathrm{OOH}^{*}, \mathrm{O}^{*}$, $\mathrm{OH}^{*}, d$-band centers and overpotentials. Free energy of $\mathrm{OOH}^{*}$, $\mathrm{O}^{*}, \mathrm{OH}^{*}$ on Co-TCNQ with strain, $d$-band centers and overpotentials. LDOSof TM-TCNQ monolayers and $d$-band centers. Scaling relations of the adsorption energies on TM-TCNQ monolayers by coordinating $\mathrm{Cl}, \mathrm{CO}, \mathrm{NO}, \mathrm{CN}$ as axial ligands. Binding energies of the first and the second ligands on TM-TCNQ. 
Overpotentials ( $\eta$ ) of TM-TCNQ monolayer (TM= Mn, Fe, Co, Ir) toward ORR and OER under strain. Scaling relations of the adsorption energies of $* \mathrm{OOH}$ vs. ${ }^{*} \mathrm{OH}$ and $* \mathrm{O}$ vs. $* \mathrm{OH}$ on $\mathrm{TM}-$ TCNQ monolayers by strain. Coordinates of Fe-TCNQ.

See DOI: $10.1039 / \mathrm{x} 0 \mathrm{xx} 00000 \mathrm{x}$

\section{Notes and references}

1. McMichael, A. J.; Woodruff, R. E.; Hales, S., Climate change and human health: present and future risks. The Lancet 2006, 367, 859-869.

2. $\quad$ Nguyen, T. V.; White, R. E., A water and heat management model for Proton-Exchange-Membrane fuel cells. Journal of the Electrochemical Society 1993, 140, 2178-2186.

3. Liu, H.; Logan, B. E., Electricity generation using an aircathode single chamber microbial fuel cell in the presence and absence of a proton exchange membrane. Environmental science \& technology 2004, 38, 4040-4046.

4. Sealy, C., The problem with platinum. Materials Today 2008, 11, 65-68.

5. Reier, T.; Oezaslan, M.; Strasser, P., Electrocatalytic oxygen evolution reaction (OER) on Ru, Ir, and Pt catalysts: a comparative study of nanoparticles and bulk materials. Acs Catalysis 2012, 2, 1765-1772.

6. Suen, N.-T.; Hung, S.-F.; Quan, Q.; Zhang, N.; Xu, Y.-J.; Chen, H. M., Electrocatalysis for the oxygen evolution reaction: recent development and future perspectives. Chemical Society Reviews 2017, 46, 337-365.

7. Stoerzinger, K. A.; Diaz-Morales, O.; Kolb, M.; Rao, R. R.; Frydendal, R.; Qiao, L.; Wang, X. R.; Halck, N. B.; Rossmeisl, J.; Hansen, H. A., Orientation-Dependent Oxygen Evolution on RuO2 without Lattice Exchange. ACS Energy Letters 2017, 2, 876-881. 8. Jaouen, F.; Proietti, E.; Lefèvre, M.; Chenitz, R.; Dodelet, J.P.; Wu, G.; Chung, H. T.; Johnston, C. M.; Zelenay, P., Recent advances in non-precious metal catalysis for oxygen-reduction reaction in polymer electrolyte fuel cells. Energy \& Environmental Science 2011, 4, 114-130.

9. Huang, Z. F.; Wang, J.; Peng, Y.; Jung, C. Y.; Fisher, A.; Wang, X., Design of Efficient Bifunctional Oxygen

Reduction/Evolution Electrocatalyst: Recent Advances and Perspectives. Advanced Energy Materials 2017.

10. Shao, M.; Chang, Q.; Dodelet, J.-P.; Chenitz, R., Recent advances in electrocatalysts for oxygen reduction reaction.

Chemical reviews 2016, 116, 3594-3657.

11. Gong, K.; Du, F.; Xia, Z.; Durstock, M.; Dai, L., NitrogenDoped Carbon Nanotube Arrays with High Electrocatalytic Activity for Oxygen Reduction. Science 2009, 323, 760-764.

12. Sorokin, A. B., Phthalocyanine metal complexes in catalysis. Chemical reviews 2013, 113, 8152-8191.

13. Abel, M.; Clair, S.; Ourdjini, O.; Mossoyan, M.; Porte, L., Single layer of polymeric Fe-phthalocyanine: an organometallic sheet on metal and thin insulating film. Journal of the American Chemical Society 2010, 133, 1203-1205.

14. Li, Y.; Sun, Q., The superior catalytic CO oxidation capacity of a Cr-phthalocyanine porous sheet. Scientific reports 2014, 4.

15. Wang, Y.; Yuan, H.; Li, Y.; Chen, Z., Two-dimensional ironphthalocyanine (Fe-Pc) monolayer as a promising single-atomcatalyst for oxygen reduction reaction: a computational study. Nanoscale 2015, 7, 11633-11641.

16. Deng, Q.; Pan, J.; Yin, X.; Wang, X.; Zhao, L.; Kang, S.-g.; Jimenez-Cruz, C. A.; Zhou, R.; Li, J., Toward high permeability, selectivity and controllability of water desalination with FePc nanopores. Physical Chemistry Chemical Physics 2016, 18, 81408147.

17. Deng, Q.; Zhao, L.; Gao, X.; Zhang, M.; Luo, Y.; Zhao, Y., Single Layer of Polymeric Cobalt Phthalocyanine: Promising LowCost and High-Activity Nanocatalysts for CO Oxidation. Small 2013, 9, 3506-3513.
18. Haynes, W.; Lide, D., CRC handbook of chemistry and physics: a ready-reference book of chemical and physical data. 2011. Boca Raton, FL.: CRC Press: 2011.

19. Hansen, H. A.; Rossmeisl, J.; Nørskov, J. K., Surface Pourbaix diagrams and oxygen reduction activity of $\mathrm{Pt}, \mathrm{Ag}$ and $\mathrm{Ni}$ (111) surfaces studied by DFT. Physical Chemistry Chemical Physics 2008, 10, 3722-3730.

20. Greeley, J.; Stephens, I.; Bondarenko, A.; Johansson, T. P.; Hansen, H. A.; Jaramillo, T.; Rossmeisl, J.; Chorkendorff, I.; Nørskov, J. K., Alloys of platinum and early transition metals as oxygen reduction electrocatalysts. Nature chemistry 2009, 1, 552.

21. Gao, G.; Waclawik, E. R.; Du, A., Computational screening of two-dimensional coordination polymers as efficient catalysts for oxygen evolution and reduction reaction. Journal of Catalysis 2017, 352, 579-585.

22. Lahiri, N.; Lotfizadeh, N.; Tsuchikawa, R.; Deshpande, V. V.; Louie, J., Hexaaminobenzene as a building block for a Family of 2D Coordination Polymers. Journal of the American Chemical Society 2016, 139, 19-22.

23. Nafady, A.; O'Mullane, A. P.; Bond, A. M., Electrochemical and photochemical routes to semiconducting transition metaltetracyanoquinodimethane coordination polymers. Coordination Chemistry Reviews 2014, 268, 101-142.

24. Zhang, X.; Saber, M. R.; Prosvirin, A. P.; Reibenspies, J. H.; Sun, L.; Ballesteros-Rivas, M.; Zhao, H.; Dunbar, K. R., Magnetic ordering in TCNQ-based metal-organic frameworks with host-guest interactions. Inorganic Chemistry Frontiers 2015, 2, 904-911.

25. Ma, Y.; Dai, Y.; Wei, W.; Yu, L.; Huang, B., Novel TwoDimensional Tetragonal Monolayer: Metal-TCNQ Networks. The Journal of Physical Chemistry A 2013, 117, 5171-5177.

26. Zhu, G.; Sun, Q., Recent advances in computational studies of organometallic sheets: magnetism, adsorption and catalysis. Computational Materials Science 2016, 112, 492-502. 27. Deng, Q.; Wu, T.; Chen, G.; Hansen, H. A.; Vegge, T., Combinatorial Selection of Two-dimensional 3d-TM-

tetracyanoquinodimethane (TM-TCNQ) Monolayer as High-Activity Nanocatalysts for CO Oxidation. Physical Chemistry Chemical Physics 2018.

28. Wang, N.; Feng, L.; Shang, Y.; Zhao, J.; Cai, Q.; Jin, P., Twodimensional iron-tetracyanoquinodimethane (Fe-TCNQ) monolayer: an efficient electrocatalyst for the oxygen reduction reaction. RSC Advances 2016, 6, 72952-72958.

29. Nørskov, J. K.; Rossmeisl, J.; Logadottir, A.; Lindqvist, L.; Kitchin, J. R.; Bligaard, T.; Jonsson, H., Origin of the overpotential for oxygen reduction at a fuel-cell cathode. The Journal of Physical Chemistry B 2004, 108, 17886-17892.

30. Rossmeisl, J.; Logadottir, A.; Nørskov, J. K., Electrolysis of water on (oxidized) metal surfaces. Chemical physics 2005, 319, 178-184.

31. Man, I. C.; Su, H. Y.; Calle-Vallejo, F.; Hansen, H. A.; Martínez, J. I.; Inoglu, N. G.; Kitchin, J.; Jaramillo, T. F.; Nørskov, J. K.; Rossmeisl, J., Universality in oxygen evolution electrocatalysis on oxide surfaces. ChemCatChem 2011, 3, 1159-1165.

32. Norsko, J., Chemisorption on metal surfaces. Reports on Progress in Physics 1990, 53, 1253.

33. Perdew, J. P.; Burke, K.; Ernzerhof, M., Generalized gradient approximation made simple. Physical Review Letters 1996, 77, 3865-3868.

34. Larsen, A.; Mortensen, J.; Blomqvist, J.; Castelli, I.; Christensen, R.; Dulak, M.; Friis, J.; Groves, M.; Hammer, B.; Hargus, C., The Atomic Simulation Environment-A Python library for working with atoms. Journal of Physics: Condensed Matter 2017. 35. Henkelman, G.; Uberuaga, B. P.; Jónsson, H., A climbing image nudged elastic band method for finding saddle points and minimum energy paths. The Journal of chemical physics 2000, 113, 9901-9904.

36. Bitzek, E.; Koskinen, P.; Gähler, F.; Moseler, M.; Gumbsch, P., Structural relaxation made simple. Physical review letters 2006, 97, 170201. 
37.

Calle-Vallejo, F.; Martínez, J. I.; Rossmeisl, J., Density functional studies of functionalized graphitic materials with late transition metals for oxygen reduction reactions. Physical Chemistry Chemical Physics 2011, 13, 15639-15643.

38. Rossmeisl, J.; Qu, Z.-W.; Zhu, H.; Kroes, G.-J.; Nørskov, J. K., Electrolysis of water on oxide surfaces. Journal of Electroanalytical Chemistry 2007, 607, 83-89.

39. Nørskov, J., Electronic factors in catalysis. Progress in surface science 1991, 38, 103-144.

40. Nørskov, J. K.; Bligaard, T.; Logadottir, A.; Bahn, S.; Hansen, L. B.; Bollinger, M.; Bengaard, H.; Hammer, B.; Sljivancanin, Z.; Mavrikakis, M., Universality in heterogeneous catalysis. Journal of Catalysis 2002, 209, 275-278.

41. Tripković, V.; Skúlason, E.; Siahrostami, S.; Nørskov, J. K.; Rossmeisl, J., The oxygen reduction reaction mechanism on Pt (1 1 1) from density functional theory calculations. Electrochimica Acta 2010, 55, 7975-7981.

42. Luo, G.; Wang, Y.; Li, Y., Two-dimensional iron-porphyrin sheet as a promising catalyst for oxygen reduction reaction: a computational study. Science Bulletin 2017, 62, 1337-1343.

43. Bezerra, C. W.; Zhang, L.; Lee, K.; Liu, H.; Marques, A. L.; Marques, E. P.; Wang, H.; Zhang, J., A review of Fe-N/C and Co$\mathrm{N} / \mathrm{C}$ catalysts for the oxygen reduction reaction. Electrochimica Acta 2008, 53, 4937-4951.

44. Holst-Olesen, K.; Reda, M.; Hansen, H. A.; Vegge, T.; Arenz, M., Enhanced Oxygen Reduction Activity by Selective Anion Adsorption on Non-Precious Metal Catalysts. ACS Catalysis 2018.

45. Faraggi, M. N.; Jiang, N.; Gonzalez-Lakunza, N.; Langner, A.; Stepanow, S.; Kern, K.; Arnau, A., Bonding and charge transfer in metal-organic coordination networks on $\mathrm{Au}$ (111) with strong acceptor molecules. The Journal of Physical Chemistry C 2012, 116, 24558-24565.

46. Enyashin, A. N.; Makurin, Y. N.; Ivanovskii, A. L., Ab initio study of dititanium endofullerenes: D-5d-and D-5h-Ti-2@C-80. Computational Materials Science 2006, 36, 26-29.

47. Cahangirov, S.; Sahin, H.; Le Lay, G.; Rubio, A., Strain engineering of 2D materials. In Introduction to the Physics of Silicene and other 2D Materials, Springer: 2017; pp 87-96.

48. Roldán, R.; Castellanos-Gomez, A.; Cappelluti, E.; Guinea, F., Strain engineering in semiconducting two-dimensional crystals. Journal of Physics: Condensed Matter 2015, 27, 313201.

49. Bissett, M. A.; Tsuji, M.; Ago, H., Strain engineering the properties of graphene and other two-dimensional crystals. Physical Chemistry Chemical Physics 2014, 16, 11124-11138.

50. Scalise, E.; Houssa, M.; Pourtois, G.; Afanas'ev, V.; Stesmans, A., Strain-induced semiconductor to metal transition in the two-dimensional honeycomb structure of MoS 2. Nano Research 2012, 5, 43-48.

51. Kou, L.; Du, A.; Chen, C.; Frauenheim, T., Strain engineering of selective chemical adsorption on monolayer MoS 2. Nanoscale 2014, 6, 5156-5161.

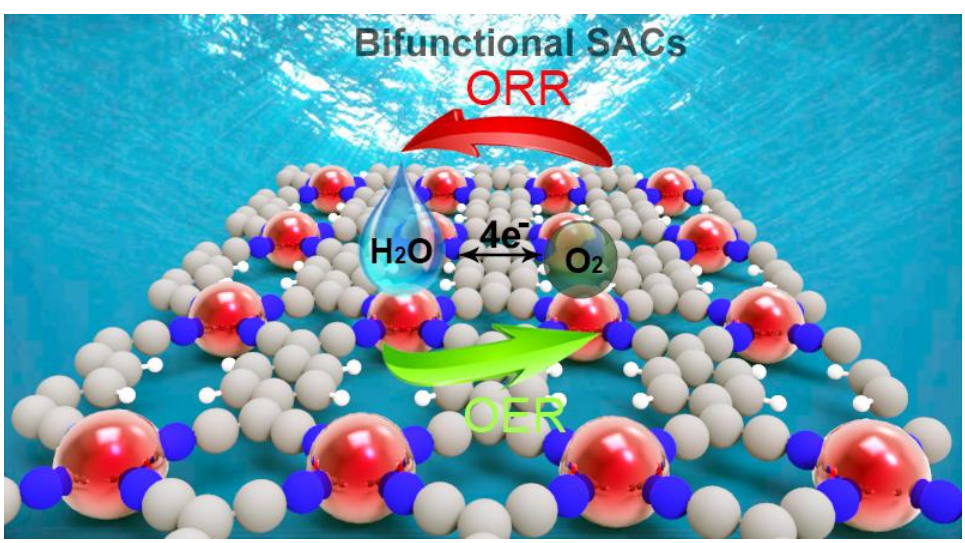

TOC: Functionalized Fe-TCNQ monolayer serves as high-activity bifunctional catalysts toward ORR and OER 